\title{
The Virtual Community: Interaktivitas pada Komunikasi Peer-to-Peer di Balik Jaringan Protokol Berbagi Berkas BitTorrent
}

\author{
Dhita Widya Putri \\ STIKOM The London School of Public Relations - Jakarta \\ E-mail: dhita.wp@lspr.edu
}

\begin{abstract}
Abstrak
Salah satu perubahan terbesar di dunia selama kurang lebih 55 tahun terakhir ini adalah pertumbuhan internet, dimana internet memungkinkan hampir semua orang di belahan dunia dapat saling terhubung dan berkomunikasi dengan cepat dan mudah. Selain itu, internet mengubah cara berkomunikasi yang tadinya bermodel "satu-untuk-banyak" menjadi "banyakuntuk-banyak", yaitu komunikasi yang lebih terdesentralisasi dan lebih demokratis. Hal ini memunculkan fenomena komunitas maya atau virtual community, dimana orang-orang yang memiliki ketertarikan yang sama dapat berkumpul dan berbagi satu sama lain dalam satu dunia, yaitu dunia maya. Disini terjadi komunikasi antara komputer satu dengan komputer lain yang terhubung secara langsung, disebut dengan "P2P" atau komunikasi peer-to-peer. Biasanya aktivitas ini digunakan sebagai sarana untuk berbagi berkas dengan cara mengunggah ataupun mengunduh didukung oleh sebuah protokol bernama Bittorrent. Hasil penelitian menunjukkan bahwa terjadi proses interaktivitas yang bersifat kolaboratif, yaitu ketika seorang seeder telah berhasil mengunduh berkas secara penuh dan melakukan proses seeding kepada peer lainnya dengan saling support satu sama lain. Padahal, keberadaan mereka bersifat semu dan anonym. Metode yang digunakan adalah kualitatif dengan teknik pengumpulan data berupa penelusuran data online dan wawancara, serta Interaktivitas sebagai konsep utama dalam tinjauan pustaka.
\end{abstract}

Kata Kunci: Virtual Community, Komunikasi peer-to-peer, berbagi berkas di internet, media online

\begin{abstract}
One of the biggest changes in the world in this past 55 years is the growth of the Internet, where it allows almost everyone in the world can connect and communicate each other with fast and easily. In addition, the Internet changed the way communication from "oneto-many" to "many-to-many", which is more decentralized and democratic. This gave rise of virtual community phenomenon, where people who have the same interests can get together and share each other in the virtual world. There is a communication between computers directly, called "P2P" or peer-to-peer communication. This activity is used for file sharing by uploading or downloading that supported by a protocol called BitTorrent. The results showed that there is a process of collaborative interactivity, when a seeder had successfully downloaded the full files and seeding it to other peer to support each other eventhough they are in pseudo-community and anonimity. The method used is qualitative with data collection techniques such as online data searches and interviews, also interactivity as a key concept for the literature review.
\end{abstract}

Keywords: Virtual Community, Peer-to-peer communication, file sharing at the internet, online media 


\section{PENDAHULUAN}

Perubahan pola komunikasi yang saat ini terjadi pada masyarakat ditandai dengan munculnya internet. Dimana internet memungkinkan hampir semua orang di belahan dunia dapat saling terhubung dan berkomunikasi tanpa batas. Selain itu, internet mengubah cara berkomunikasi yang tadinya bermodel "satu-untuk-banyak" (model pada media konvensional misalnya seperti televisi) menjadi "banyak-untuk-satu" (dari jutaan pengguna ke sebuah situs) bahkan "banyak-untuk-banyak" (forum online, milis, dsb) dengan cara komunikasi yang lebih terdesentralisasi dan lebih demokratis. Internet merupakan jaringan komputer dunia yang mengembangkan ARPANET, yaitu suatu sistem komunikasi berkaitan dengan pertahanan dan keamanan yang dikembangkan pada tahun 1960-an (Severin dan Tankard, 2011). Kontribusinya akan sistem komunikasi yang berjaringan ini bermanfaat untuk masyarakat, dengan hanya melalui sebuah komputer, internet hadir untuk publik sebagai media massa baru.

Perkembangan internet terbilang fenomenal. Baik dari jumlah pengguna maupun jumlah komputer induknya (host computer). Host computer dapat mengukur besarnya perkembangan internet beberapa tahun silam karena, Host computer merupakan tempat penyimpanan informasi melalui jaringan. Menurut Network Wizards (1999), Jumlah Host Computer meningkat dari 5,9 juta hingga 43,2 juta dari tahun 1995-1999. Pada bulan Agustus 2015, Tim WeAreSocial Singapore mencatat bahwa pengguna aktif internet dunia mencapai 3,175 juta orang (“Global Statshot: 2015”, 3 Agustus 2015). Di Indonesia sendiri, Asosiasi Penyelenggara Jasa Internet Indonesia (APJII) mengungkapkan jumlah pengguna internet di Indonesia mencapai 88 juta orang hingga akhir tahun 2014 (APJII, 2015: 20). Salah satu faktor penunjang perkembangan internet yang begitu pesat adalah sifatnya yang cepat dan mudah. Dengan begitu, masyarakat dari berbagai belahan dunia dapat saling berkomunikasi satu sama lain tanpa batas dalam satu dunia baru bernama cyberspace.

Gambar 1

Global Digital Statistics Agustus 2015

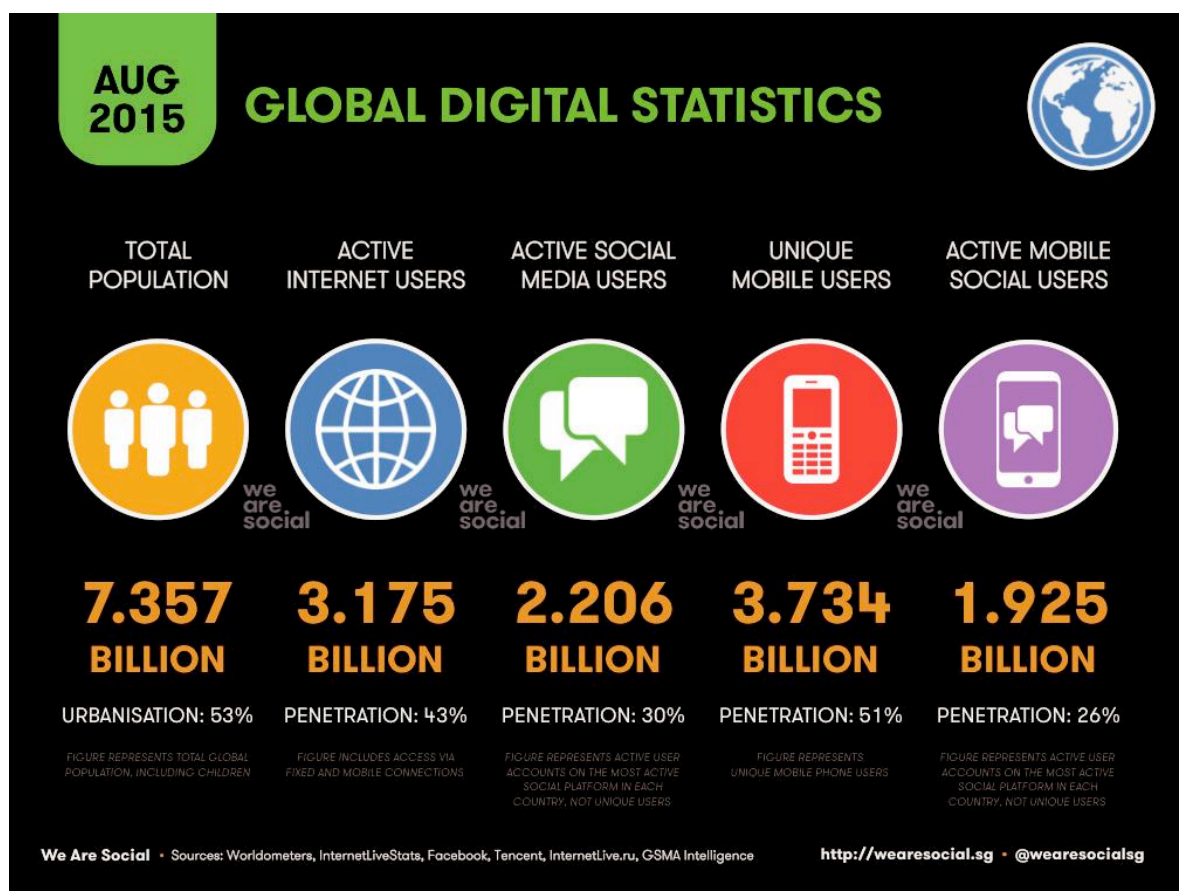

Sumber: http://wearesocial.net/blog/2015/08/global-statshot-august-2015/ 
Cyberspace adalah nama lain dari dunia maya. Kata ini berawal dari sebuah novel berjudul "Neucromancer" karya William Gibson (Goldberg, 1996). Dikatakan bahwa dunia maya merupakan realita yang terhubung secara global, didukung komputer, berakses komputer, multidimensi, artifisial, dan virtual (Benedikt, 1991: 122-123). Dalam perkembangannya saat ini, dunia maya atau cyberspace merupakan istilah yang melekat dengan "world wide web" atau situs, internet, milis elektronik, kelompok-kelompok, forum diskusi, ruang ngobrol atau "chat room", permainan interaktif, dan surat elektronik atau "e-mail" (Turkle, 1995).

Seiring dengan perkembangan zaman, dunia maya memunculkan berbagai fenomena. Salah satunya adalah fenomena komunitas maya atau virtual community. Komunitas ini lahir dengan wujud komunikasi elektronik berupa bulletin komputer dengan sambungan modem di tahun 1970-an (Severin dan Tankard, 2011: 447). Semenjak itu, istilah-istilah lain bermunculan seperti ruang chatting, email, mailing list, forum, dan lain-lain yang dimanfaatkan komunitas-komunitas sebagai 'wadah' untuk berkomunikasi dan secara virtual. Virtual community atau komunitas virtual merupakan tempat dimana orang-orang yang memiliki ketertarikan yang sama dapat berkumpul dan berbagi satu sama lain (Rheingold, 1993). Virtual community juga merupakan ruang yang mendukung seseorang untuk dapat berhubungan dengan orang lain yang memiliki pemikiran dan minat yang sama (Lin, 2006) dengan bantuan sebuah situs maupun jejaring sosial.

Virtual community memungkinkan terjadinya aktivitas berbagi berkas atau file sharing terhadap sesama pengguna. Menurut Yudha dan Prayudi (2013), umumnya pengguna komputer memerlukan media penyimpanan tambahan untuk memenuhi kebutuhannya (contohnya untuk kebutuhan pekerjaan, hiburan, dan sebagainya). Namun tidak semua pengguna memiliki kapasitas penyimpanan yang besar dalam komputernya. Aktivitas file sharing ini dapat membantu untuk mengatasi hal tersebut dengan cara menampung data dari komputer pengguna lain atau digunakan sebagai tempat menyimpan berkas yang kemudian dapat digunakan secara bersama-sama. Teknik file sharing ini pun bermacam-macam, salah satu jenisnya yang paling digunakan adalah dengan bantuan protokol Bittorent.

Bittorent merupakan sebuah protokol berbagi berkas atau file sharing yang secara langsung dari komputer ke komputer dengan prinsip peer-to-peer communication (Schulze and Mochalski, 2009). Protokol ini dibuat dengan bahasa pemrograman python yang dibuat oleh Bram Cohen pada tahun 2001. Cara kerjanya yaitu satu komputer akan terhubung dengan milyaran komputer dari seluruh dunia. Disanalah tersedia sejumlah data-data berupa film, lagu, perangkat-perangkat lunak, buku, dan lain sebagainya degan kapasitas yang besar. Bittorent akan membantu dalam hal pendistribusian data menjadi bagian-bagian kecil sehingga data-data yang berukuran besar tersebut akan mudah untuk diakses.

Untuk dapat melakukan file sharing, seseorang harus memiliki klien Bittorent, yaitu program komputer yang dapat menjalankan protokol Bittorent. Klien Bittorent yang biasanya digunakan antara lain; uTorrent, Xunlei, Transmission, qBittorent, Vuze, Deluge, dan BitComet (Hinks, 2015). Dalam prosesnya, Bittorent akan dibantu dengan Bittorent Tracker, yaitu server sentral yang menghubungkan peers yang satu dengan lainnya, juga menyediakan daftar berkas-berkas yang ada untuk dibagikan nantinya ("For Developers", 2008). Dalam perkembangannya, protokol berbagi berkas ini menuai sejumlah pro dan kontra. Misalnya Bittorrent dimanfaatkan sebagai sarana pendistribusian berkas, di Hollywood Studio, yaitu mereka dengan mudah mendistribusikan konten-konten berlisensi dari situsnya, juga untuk kebutuhan individu dan kelompok misalnya berbagi perangkat lunak (software), film, musik, 
dan lain sebagainya. Namun, banyak juga yang berpendapat kalau sarana berbagi file ini merupakan bentuk dari pembajakan dan pelanggaran hak cipta.

Ada beberapa istilah yang dipakai dalam komponen Bittorent antara lain (Chaudhary, 2013):

1. Torrent File: metadata berkas atau file yang akan diunduh. Biasanya kapasitas pada berkas ini kecil-kecil, hanya beberapa kilobyte saja.

2. Bittorrent atau Torrent: sebuah protokol dengan komunikasi berbasis P2P yang memperbolehkan satu komputer terhubung dengan komputer lain untuk mengirim atau menerima berkas atau distribusi data

3. Seed/seeder: orang yang telah secara utuh memiliki berkas berupa file torrent. Dia merupakan orang yang membuat file torrent asli ataupun orang yang telah mengunduh sebuah berkas dan secara otomatis mengunggahnya. Jadi, semakin banyak jumlah seeders, maka presentase keberhasilan mengunduh berkas semakin besar.

4. Leecher: Orang yang baru saja mengunduh sebuah file torrent namun sama sekali tidak memiliki sebagian atau keseluruhan dari sebuah berkas. Peer adalah bagian dari leecher yang sama sekali belum memiliki sebuah berkas. Istilah peer juga dapat disebut dengan client atau user. Setelah peer atau client mengunggah sebuah berkas, maka akan menjadi seeder.

5. Tracker merupakan pusat yang menghubungkan Peers satu dengan yang lainnya, dengan proses komunikasi, pertukaran data, juga menyediakan informasi mengenai peer yang terhubung. Ada dua jenis tracker yaitu open tracker dan closed tracker.

6. Swarm adalah sekumpulan user atau peers yang sedang terhubung satu sama lain untuk mengunduh berkas secara bersamaan

Sebenarnya ada beberapa istilah lain pada Bittorent, namun disini peneliti hanya memfokuskan kepada istilah-istilah yang dipakai pada proses komunikasi peer-to-peer saja. File torrent terdiri dari satu atau beberapa berkas yang disebut dengan metadata. Metadata ini dibuat sebelum dibagikan ke sesama pengguna dengan bentuk sekumpulan berkas yang disebut dengan entity. Dalam proses sharing atau berbagi berkas, dari pengguna satu kepada pengguna lain (peers) dihubungkan dengan tracker, yaitu jaringan yang mengkordinasikan mereka satu sama lain selama proses pengunduhan berlangsung. Tracker juga berfungsi sebagai wadah yang mengumpulkan seluruh pengguna yang mengunduh berkas yang sama untuk terbentuknya swarm (ekosistem dari seluruh pengguna). Dalam proses mengunduh sebuah file torrent, dibutuhkan aplikasi yang dapat menjalankan file tersebut dengan sebutan Bittorrent Client. Melalui Bittorrent client ini, dapat dilihat berapa peers yang saling terhubung satu sama lain untuk kegiatan mengunduh, juga dapat dilihat peer yang mana yang memiliki berkas yang mana.

Sebagai proses awal berbagi berkas, pengguna menjelajahi situs-situs penampung file torrent yang dikenal dengan forum. Ada berbagai macam forum yang dikenal di kalangan pengguna, misalnya Pirate Bay, Kickasstorrents, Torrentz, Extratorrent, Kaskus, dan sebagainya. Setelah itu, pengguna memilih atau meminta berkas apa yang diinginkan. Selanjutnya, pengguna akan langsung mengunduh berkas tersebut dan membukanya dengan program Bittorrent client. Client membantu pengguna terhubung dengan tracker, lalu akan didapatkan daftar peers yang sedang mentransfer potongan-potongan berkas berupa file torrent. Selain itu, Client juga akan menghubungkan antara peer-to-peer satu sama lain untuk membentuk swarm. Ketika peers saling terhubung, mereka akan memulai untuk berbagi potongan-potongan berkas secara bersama-sama. 
Lancar tidaknya proses pertukaran data sangat ditentukan oleh Client, dimana Client akan menentukan kepada siapa data akan dikirimkan. Client dari seorang peer akan memilih untuk mengirim data kepada peer lain yang juga mengirimkan data kepadanya. Disini terjadi pertukaran yang adil, dimana sesama peers saling mengirim juga menerima berkas. Namun, pada kenyataannya hal ini menjadikan situasi yang tidak optimal, karena apabila ada seorang peer yang baru saja bergabung tidak dapat menerima sebuah berkas, karena dia belum memiliki berkas yang akan ditukar. Bahkan, ada peers yang sudah memiliki koneksi baik tapi tidak memiliki inisiatif untuk bertukar data. Dalam mengantisipasi hal ini, Bittorrent client akan mencadangkan sebagian bandwith (jumlah data yang dapat ditransfer dari satu titik ke titik lain dalam satuan bit per second/bps) untuk mengirimkan potongan-potongan berkas kepada peers secara acak, dengan tujuan untuk mendapatkan peers yang lebih baik juga memastikan peer yang baru dapat bergabung kedalam swarm.

Kegiatan berbagi berkas dengan bantuan BIttorrent ini terbilang praktis dalam mendistribusikan dan pemberian akses berupa informasi digital, program-program komputer, video, audio, dokumen, serta buku-buku elektronik. Semua pengguna dapat saling terhubung dengan mudah dan cepat dengan sesamanya dari berbagai belahan dunia dengan bantuan jaringan komunikasi komunikasi peer-to-peer atau P2P. Jaringan P2P (peer-to-peer) dikenal dengan jaringan yang bertemakan "pertemanan atau persahabatan". Istilah ini dibuat dengan tujuan untuk mengisyaratkan sebuah hubungan yang setara diantara sesama peers (pengguna). Hubungan ini menghasilkan interaksi langsung antara komputer satu dengan komputer lain. Secara teknis, P2P merupakan jaringan yang memungkinkan sebuah komputer bertindak sebagai pendistribusi maupun penerima berkas-berkas satu pengguna dengan pengguna lainnya. Dengan kata lain, setiap peer bertindak sebagai client juga bertindak sebagai server. Tujuan utama dari P2P yaitu agar semua peers dapat menyediakan skaligus memanfaatkan sumber komputer masing-masing, seperti bandwith juga media penyimpanannya. Sifatnya yang terdistribusi ini dapat meningkatkan kestabilan sistem.

Dalam perkembangannya, ada 2 macam model jaringan komputer (Ghosemajumder, 2002) yaitu model yang tersentralisasi dan terdesentralisasi. Model tersentralisasi disebut juga dengan "server based network" dimana model tersentralisasi tejadi saat semua peer terhubung kepada satu server. Server ini bertindak sebagai penghubung antara peer satu dengan yang lainnya. Sedangkan terdesentralisasi atau "Peer-to-peer Network" membuat semua peer memiliki status yang sama dalam satu jaringan, dapat dikatakan bahwa semua pengguna bertindak sebagai server maupun client. Kekurangan dari model terdesentralisasi yaitu seorang peer tidak akan mengetahui isi (konten), jumlah, maupun alamat peer lainnya yang sedang terhubung dalam jaringan. 
Gambar 3

Model Tersentralisasi dan model terdesentralisasi

\section{Server Based Network Peer to Peer Network}
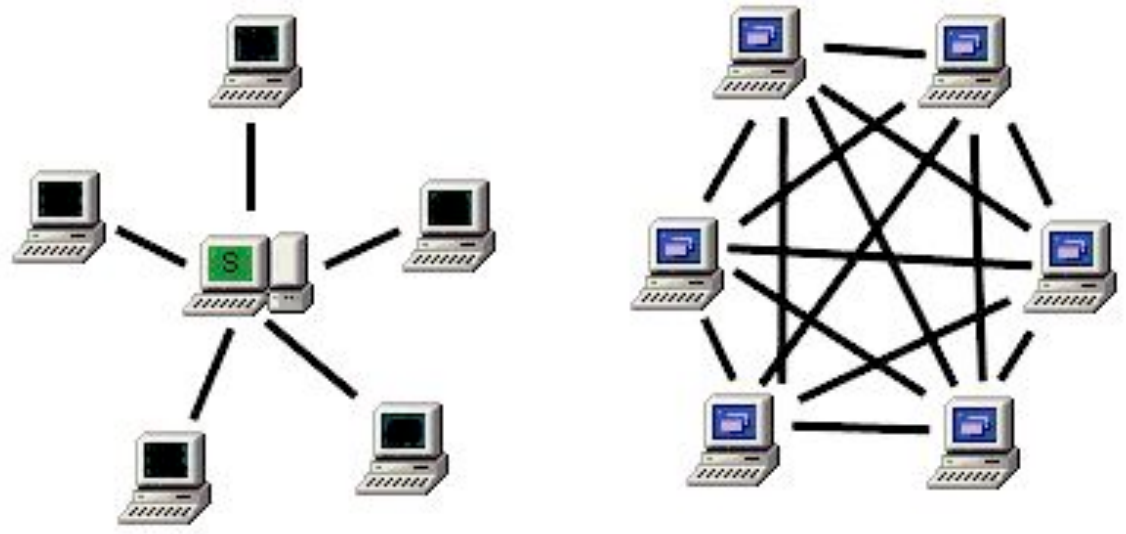

Sumber: http://shareaza.sourceforge.net/mediawiki/images/1/1a/Networks.png

Dari latar belakang yang telah dipaparkan diatas, maka dirumuskan permasalahan "bagaimana proses interaktivitas yang terjadi dalam komunikasi peer-to-peer dibalik jaringan protokol berbagi berkas Bittorrent?" dengan tujuan untuk dapat menilik aktivitas komunikasi dalam komunitas virtual (virtual community) dibalik tren berbagi berkas di dunia maya.

\section{TINJAUAN TEORI/KONSEP}

\section{Interaktivitas}

Interaktivitas merupakan salah satu konsep dalam studi komunikasi dunia baru atau new media. Interaktivitas dapat juga dikatakan sebagai fitur dalam dunia cyber. Kata interaktivitas memiliki dua makna yang berbeda, yaitu komunikasi dengan sebuah komputer. Dimana manusia mengoperasikan berbagai perangkat lunak dan memberikan perintah kepada pemrograman komputer (Dillon and Leonard, 1998: 144). Sedangkan makna lain, interaktivitas dapat dikatakan sebagai komunikasi yang terjalin antar manusia dengan bantuan komputer. Komunikasi yang terjalin contohnya seperti berdialog secara mutual dan bertukar peran (William, Rice, and Rogers, 1998: 10). Istilah ini penting dalam dalam dunia internet, karena ketika seseorang masuk kedalam dunia maya kedua interaktivitas tersebut akan terjadi secara bersamaan. Interaktivitas merupakan konsep yang kompleks dan belum ada definisi yang standarm sehingga interaktivitas dianggap sebagai konsep yang multidimensi.

Menurut McMIllan dan Downes (1988), terdapat 6 dimensi interaktivitas antara lain:

1. Persuasi - menginformasikan

2. Kontrol lemah - kontrol tinggi

3. Aktivitas rendah - aktivitas tinggi

4. Satu arah - dua arah

5. Waktu tertentu - waktu fleksibel

6. Kesadaran rendah terhadap tempat - kesadaran tinggi terhadap tempat 
Dalam keenam dimensi tersebut dijelaskan bahwa dalam prosesnya, terjadi interaktivitas dengan cara pemberian informasi daripada persuasi, lebih banyak kontrol oleh pengguna, lebih banyak aktivitas oleh pengguna, bukan komunikasi satu arah melainkan dua arah, komunikasi yang terjadi pada waktu yang fleksibel, dan komunikasi yang terjadi di tempat yang tidak sebenarnya. Selain itu, terdapat 5 dimensi lain menurut Ha dan James (1995) bahwa interaktivitas memiliki:

1. Daya hibur, yaitu fitur-fitur yang memiliki partisipan misalnya game dan kuis

2. ilihan, dimana pengguna diberikan alternative misalnya dapat memulai atau mengakhiri komunikasi setiap saat

3. Daya sambung, internet memberikan situs yang memuat informasi lengkap dan melibatkan pengguna, sehingga pengguna akan melakukan kunjungan berulang

4. Koleksi Informasi, kumpulan data demografis, psikografis, dan karakteristik pengguna yang dapat dikumpulkan ketika sedang emngakses sebuah situs

5. Komunikasi timbal balik, yaitu komunikasi dua arah, misalnya chatting room atau email

Menurut Kiousis (2002), interaktivitas merujuk kepada 4 faktor antara lain; kedekatan sosial dengan orang lain, aktivasi pengindraan, kecepatan yang diamati, dan kehadiran jarak jauh. Dalam definisi ini lebih banyak tergantung pada persepsi pengguna daripada kualitas media yang obyektif.

\section{Teori Computer Mediated Communication (CMC)}

Computer Mediated Communication (CMC) merupakan proses komunikasi lewat media komputer. Proses komunikasi ini melibatkan orang yang terlibat dalam proses untuk membentuk media untuk berbagai tujuan. CMC juga didefinisikan sebagai proses komunikasi yang terjadi antara manusia melalui perantara komputer yang berbeda. Hal ini dimaksudkan bukanlah bagaimana dua mesin atau lebih dapat berinteraksi, namun bagaimana dua orang atau lebih dapat berkomunikasi antara satu dengan lainnya menggunakan alat bantu komputer melalui program aplikasi pada komputer tersebut (Thurlow, 2005:15). Menurut penelitian Lindlof dan Schatzer (1998) mengatakan bahwa CMC berbeda dengan penggunaan media lain karena sifatnya sementara, multimodal, dengan sedikit penggunaan kode perilaku pengaturan, dan memungkinkan 'manipulasi konten oleh pengguna akhir' pada tingkat tinggi. Meskipun benar bahwa komputer menghubungkan seseorang dengan yang lain, namun pada tahap penggunaannya melibatkan perilaku soliter, pilihan dan respons individualistis, dan anonimitas yang jamak (Baym, 2002). Maka dapat dikatakan bahwa hubungan yang tercipta atau termediasikan oleh mesin-mesin komunikasi baru seringkali bersifat sementara, dangkal, dan tanpa komitmen (McQuail, 2011).

\section{Komunitas Virtual (Virtual Community)}

Konsep 'komunitas' memiliki posisi yang penting dalam dunia sosial, terkhusus untuk melihat dampak perubahan sosial pada masyarakat. Komunitas adalah sekelompok orang yang berbagi tempat (atau ruangan yang terbatas), sebuah identitas, norma-norma, nilai-nilai, praktik budaya tertentu, dan biasanya cukup kecil untuk saling mengenal atau berinteraksi (McQuail, 2011). Gagasan tentang sebuah komunitas berkembang sejalan dengan komunikasi yang termediasikan komputer (CMC) yang dikenal dengan istilah komunitas virtual atau virtual community. Komunitas ini dibentuk oleh sejumlah individu melalui internet atas dasar pilihan mereka sendiriterhadap tanggapan akan suatu rangsangan (Rheingold, 1993). Komunitas virtual juga merupakan komunitas yang didirikan sengaja oleh orang-orang 
yang memiliki epentingan-kepentingan yang sama, seringkali berkisar seputar teks atau ungkapam tertentu dari tempat-tempat lain yang mereka sukai. Sifat-sifatnya antara lain; interaksi, tujuan yang sama, kesadaran akan identitas dan kepemilikan, beragam norma dan aturan tidak tertulis dengan kemungkinan akan penolakan dan pengucilan. Kelebihan dari komunitas virtual yakni terbuka dan mudah diakses (Slevin, 2000).

Menurut Turner et. al (2011), CMC dalam komunitas virtual bersifat interaktif dan termotivasi yang tidak tersedia di media massa atau lingkungan fisik terdekat. Hal ini ditunjukkan dengan kontak tatap muka dan online tidak eksklusif dan memiliki interaksi yang bersifat timbal balik. Namun, ada keraguan-keraguan terhadap keaslian dari komunitas virtual yang ada, hal ini disebut juga dengan pseudo-community atau komunitas semu (Beniger, 1987). Hal ini sesuai dengan apa yang dikatakan oleh Rheingold (1993) bahwa dalam komunitas online, identitas seringkali tidak asli atau tidak diungkapkan. Dalam hal ini misalnya informasi mengenai usia atau gender (Jones, 1997: 107). Partisipasi dalam diskusi oline dan interaksi didalamnya bersifat anonim.

\section{Komunikasi Peer-to-Peer (P2P)}

Komunikasi Peer-to-Peer yang disingkat dengan P2P merupakan proses komunikasi yang terjadi pada aplikasi-aplikasi berbagi-berkas atau file sharing yang memungkinkan para penggunanya untuk dapat berbagi, mencari, mengunduh, dan mengunggah berkas (Gong, 2010). P2P seringkali disebut dengan sistem yang menghubungkan "ujung" satu dengan "ujung" lain dengan bentuk lalulintas komunikasi yang bersifat dinamis dan partisipatif. Secara mekanisme, jaringan P2P terdiri dari beberapa komputer, dimana setiap komputer dapat saling berbagi, misalnya menggunakan suatu program bersama pada saat yang bersamaan pula. P2P diasosiasikan dengan "kolaborasi" namun tanpa adanya pusat kontrol, dengan kata lain, P2P dapat berjalan dengan sistem operasi yang terinstalasi di dalam komputer dan saling tersambung secara fisik (Ford, Srisuresh, and Kegel, 2008). Komputer

- komputer yang telah terhubung ini dapat berfungsi sebagai klien maupun server. Mereka saling bertanggungkawab atas administrasi resource komputer berupa pembuatan nama user, menentukan berkas mana yang akan dibagi, dan menandai izin akses kegiatan berbagi berkas tersebut sambil bertanggungjawab atas melakukan backup data pada komputernya masing-masing.

Ilustrasi Jaringan komunikasi Peer-to-Peer

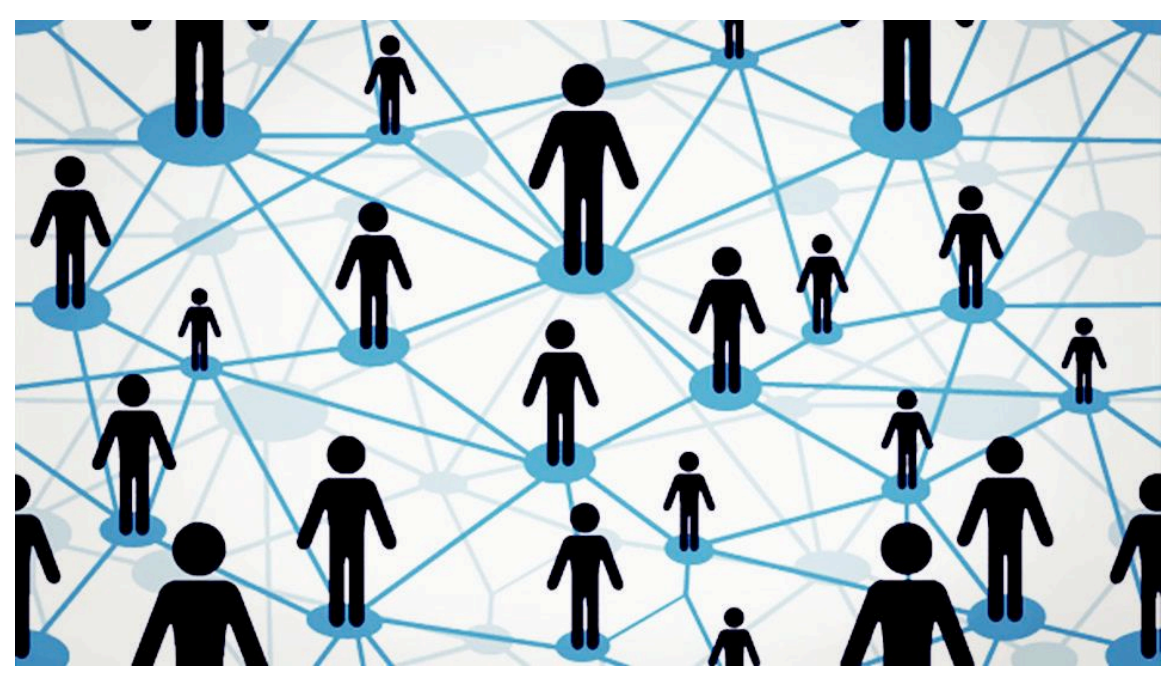

Sumber: http://fikobservatory.com/en/post/what-is-peer-to-peer-p2p/ 


\section{METODE PENELITIAN}

Penelitian ini menggunakan metode kualitatif, dengan tujuan untuk mengkonstruksi realitas dan memahami maknanya (Somantri, 2005). Metode kualitiatif merupakan metode yang memperhatikan proses, peristiwa, dan otentisitas yang mengedepankan pencarian data-data. Teknik pengumpulan data yang digunakan adalah dengan penelusuran data online sebagai data primer. Penelusuran data online adalah tata cara pencarian data melalui internet atau media jaringan lainnya yang menyediakan fasilitas online dengan cepat, mudah, dan dapat dipertanggungjawabkan secara akademis (Bungin, 2007). Data sekunder diperoleh dengan studi literatur dari buku dan jurnal, serta wawancara kepada 4 orang pengguna Bittorent sebagai pelengkap data.

\section{TEMUAN}

Peers yang merupakan pengguna dari protokol berbagi berkas Bittorent termasuk kepada komunitas virtual (virtual community) dimana mereka adalah sekumpulan orang-orang yang berasal dari berbagai tempat, saling berinteraksi, dan termediasikan dengan bantuan komputer. Sekumpulan orang-orang ini terbentuk berdasarkan pilihan mereka sendiri, karena merasa memiliki kepentingan yang sama dengan terbuka dan mudah diakses.

Proses pengumpulan data pada penelitian ini dilakukan dengan studi literature dan wawancara dengan 4 narasumber yang merupakan peers atau pengguna Bittorrent, dimana 2 orang menggunakan jenis client uTorrent dan 2 orang lagi menggunakan client Bittorrent. Para pengguna ini mengenal protokol berbagi berkas sejak tahun 2005, 2010, dan 2011. Biasanya yang seringkali diunggah dan dibagi adalah berkas-berkas berupa musik, film, buku, majalah, perangkat lunak (softwares), serial televisi, template desain, dan sound effects. Kebanyakan, berkas-berkas yang dibagikan merupakan berkas yang memiliki sifat daya hibur (Ha dan James, 1995). Aktivitas pertama yang dilakukan peers yaitu mencari forum-forum yang menyediakan alamat tautan untuk mengunduh berkas yang diinginkan, setelah itu alamat diklik sehingga client Bittorrent mulai bekerja dan proses pengunduhan pun dimulai. Setelah proses pengunduhan selesai, salah satu peer ini akan tetap menyalakan komputernya dan tetap mengaktifkan koneksi komputer, dengan tujuan agar data tersebut dapat dibagikan kepada peer lainnya, yang dinamakan dengan proses seeding. Hal ini dikatakan oleh narasumber Nugroho, yang merupakan salah satu pengguna client uTorrent "Saya mencari alamat tautan di forum yang membagikan alamat tautan, lalu menjalankan link tautan di software utorrent dan tinggal menunggu unduhan selesai. Jika saya ingin membantu proses sharing penggunan lain, saya dpt tetap mengaktifkan koneksi saya untuk membantu proses seeding." (Wawancara Data Primer, 5 Agustus 2015). Hal serupa juga dilakukan oleh para pengguna lain yang mendapatkan alamat tautan dari Kickass Torrent dan Pirate Bay (Ananda, D., Wawancara Data Primer, 6 Agustus 2015). Selain itu, salah satu narasumber mengatakan bahwa berkas-berkas yang ingin dibagi dapat dicari dengan menggunakan fitur "search" dalam forum penyedia berkasnya (Sagala, I., Wawancara Data Primer 2015). Lain halnya dengan 3 narasumber yang melakukan pengunduhan berkas dari peer lain, satu narasumber (Basworo, A., Wawancara Narasumber, 5 Agustus 2015) mengatakan bahwa dia lebih banyak melakukan pengunggahan ketimbang pengunduhan, dengan proses yang sama, namun akan diperlukan aplikasi kompresi agar kapasitas berkas-berkas tersebut tidak terlalu besar dan siap dibagikan kepada peer yang lain.

Ketika sedang melakukan proses berbagi berkas, para pengguna akan saling menjalin 
interaksi. Misalnya dalam hal berbagi koneksi untuk membantu pengguna lain atau yang biasanya disebut dengan seeding. Kedua adalah berkomunikasi di dalam forum yang telah menyediakan alamat tautan yang dibutuhkan, misalnya memberikan "thumbs up". Uniknya, para pengguna ini berasal dari tempat dan latar belakang yang berbeda-beda dan anonim, namun mereka bisa saling percaya satu sama lain bahwa berkas yang dibagikan kredibel. Hal ini dilakukan dengan cara memilah-milah terlebih dahulu forum yang memiliki nilai kredibilitas yang tinggi dan positif, setelah itu melakukan pengecekan tentang deskripsi berkas yang akan diunduh, dan biasanya dalam forum tersebut ada review dan komentar yang dapat dibaca para pengguna, serta daftar "Top Leecher dan Seeder", dengan asumsi bahwa semakin tinggi angka yang dicantumkan, maka semakin sering berkas tersebut diunduh dan bagus kualitasnya. Biasanya para pengguna operating system iOS Apple, mereka tidak takut dengan akan hadirnya virus atau junk files karena operating system ini tidak akan bias membaca berkas-berkas tersebut. Dengan begini, kecil kemungkinannya bagi peers untuk mendapatkan berkas yang tidak sesuai dengan keinginan mereka. Hal ini sesuai dengan konsep interaksi pada komunikasi dunia maya dimana komunikasi tersebut terjalin antar manusia yang dihubungkan dengan bantuan komputer (William, Rice, and Rogers, 1998: 10), khusunya ketika antar pengguna berdialog (misalnya saling mengemukakan akan berkas yang diminta dan diberikan, pemberian apresiasi apabila berkas yang dibutuhkan memenuhi kebutuhannya) serta bertukar peran (yaitu saat menjadi seeder maupun leecher) walaupun dari mereka tdak mengenal satu sama lain dan bersifat semu. Hal ini sesuai dengan apa yang dikatakan oleh Turner et. al (2011), itu komunikasi yang terbentuk bersifat interaktif dan timbal balik.

Dalam konsep interaktivitas, terdapat proses pemberian informasi. Hal ini diaplikasikan dalam kegiatan berbagi berkas pada Bittorrent, dimana sebelum mengunduh berkas yang diinginkan biasanya seorang peer akan meminta dahulu kepada moderator forum (peer lainnya), setelah itu moderator forum akan memberikan alamat tautan juga informasi yang diinginkan tentunya dengan kontrol dari yang meminta berkas. Apabila berkas yang diminta sesuai, maka proses pengunduhan dapat langsung dimulai dan ketika selesai biasanya mereka akan memberikan apresiasi, apabila berkas tidak sesuai atau mengandung berkas-berkas yang dapat membahayakan komputer, maka pengguna dapat langsung memberhentikan kegiatan pengunduhan. Disini juga terjadi komunikasi dua arah yang terjalin antara sesama peers dengan waktu yang fleksibel, dapat dilakukan kapan saja dan dimana saja dalam konteks dunia maya. Hal ini sesuai dengan apa yang dikemukakan oleh McMIllan dan Downes (1988), bahwa "terjadi interaktivitas dengan cara pemberian informasi daripada persuasi, lebih banyak kontrol oleh pengguna, lebih banyak aktivitas oleh pengguna, bukan komunikasi satu arah melainkan dua arah, komunikasi yang terjadi pada waktu yang fleksibel, dan komunikasi yang terjadi di tempat yang tidak sebenarnya." Selain itu, sesama peers juga dapat membuat pilihan, dimana mereka dapat memilih apakah mereka mau untuk memulai dan mengakhiri komunikasi yang terbentuk pada jaringan peer-to-peer, misalnya pada proses pengunduhan sorang leecher dari seorang seeder, namun leecher tersebut memberhentikan koneksinya, tanpa mau melakukan berbagi berkas lagi kepada sesamanya (yang disebut juga dengan proses hit and runner), tentunya hal ini bisa saja dilakukan dalam proses komunikasi virtual, karena sifatnya yang anonim, namun tentunya hal ini akan dapat merugikan sesama peers.

Kegiatan berbagi berkas ini dilakukan dengan tidak menentu dan tergantung kebutuhan (fleksibel). Misalnya ada film atau musik baru, juga saat membutuhkan perangkat-perangkat lunak tertentu. Selain itu, hal lain yang menjadi pertimbangan dilakukannya proses berbagi berkas adalah koneksi internet yang cepat (yaitu minimum $2 \mathrm{Mbps}$ ), forum-forum yang 
kredibel yang banyak melakukan support seeding, kapasitas penyimpanan berkas yang masih banyak di dalam komputer pengguna. Dalam hal ini, koneksi internet menjadi salah satu hal penting dalam terjadinya komunikasi peer-to-peer, karena salah satu konsep dalam interaktivitas adalah daya sambung, dimana dengan koneksi yang lancer maka akan besar kemungkinannya untuk melakukan kunjungan berulang.

Dalam prosesnya, kegiatan berbagi berkas ini ada kekurangan dan kelebihannya. Kelebihannya adalah berguna untuk para pengguna yang tidak mampu membeli berkas yang harganya mahal, proses pengunduhan berkas dapat ditahan (pause) dan dapat dilanjutkan di waktu lain juga data-data yang disajikan lengkap, sedangkan kekurangannya yaitu terkesan illegal, pembajakan (piracy), seringnya iklan pop-up yang bermunculan sehingga mengganggu penglihatan dan konsentrasi pengguna, juga banyaknya akun membagi berkas yang sama, maka hal tersebut akan dirasa tidak berguna.

Dengan adanya aplikasi ini, para narasumber mengaku bahwa mereka terbantu dan kebutuhannya terpenuhi, hal ini dikarenakan harga berkas-berkas yang asli terbilang cukup mahal, belum tersedia pada kanal dan situs di Indonesia, berkas-berkas yang disediakan umumnya gratis, efisien waktu karena tidak perlu repot mencari berkas yang dibutuhkan ke berbagai tempat, praktis dan gampang digunakan.

\section{KESIMPULAN}

Komunikasi peer-to-peer dalam kegiatan berbagi berkas pada jaringan protokol Bittorrent memungkinkan penggunanya untuk dapat berbagi satu sama lain dengan saling mengunggah dan mengunduh berkas yang diperlukan. Komunikasi ini berjalan dari "ujung" ke "ujung" dengan dinamis, interaktif, dan kolaboratif tanpa adanya pusat kontrol. Interaktivitas yang terdapat dalam aktivitas ini terjadi ketika seorang seeder telah berhasil mengunduh berkas secara penuh dan melakukan proses seeding kepada peer lainnya dengan berbagi koneksi satu sama lain, berbagi komentar atas berkas yang telah dibagikan, pemberian apresiasi sebagai bentuk kepuasan antar peers karena berkas yang diminta sesuai dengan yang dibutuhkan walaupun terdapat keraguan atas keaslian identitas (bersifat semu) dan partisipasinya anonim. Sehingga diharapkan untuk penelitian selanjutnya agar dapat mengkaji topik ini dari sudut pandang pro dan kontra nya kegiatan berbagi berkas di Internet. 


\section{DAFTAR PUSTAKA}

“For Developers". (2008). Diperoleh dari http://www.bittorrent.org/beps/bep_0001. html

APJII (Asosiasi Penyelenggara Jasa Internet Indonesia). (2015). Profil Pengguna Internet Indonesia 2014. (E-Book) diperoleh dari http://www.apjii.or.id/v2/upload/ statistik/Survey\%20APJII\%202014\%20v3.pdf

Baym, N. K. (2002). Interpersonal Life Online; dalam Lievrouw, L. A. and Livingstone, S. (ed.), The Handbook of New Media, hlm. 62-76. London: Sage

Benedikt, M. (1991). Cyberspace : Some Proposals. In M. Benedikt, Ed., Cyberspace: First Steps, pp. 119-224. Cambridge, Mass.: MIT Press.

Beniger, J. R. (1987). Personalization of Mass Media and the growth of pseudocommunity: Communication Research, 14 (3): 352-371

Bungin, B. (2007). Penelitian Kualitatif. Jakarta: Kencana

Chaudhary, P. (2013). "Torrent Terminology". [Website] Diperoleh dari http:// thegeekdaily.com/introduction-to-torrents-and-torrent-terminology/

Dillon, P. M., and Leonard, D. C., (1998). Multimedia and the Web from A to Z, 2nd ed. Phoenix, Ariz: Oryx Press.

Ford, B., Srisuresh, P., Kegel, D., (2008). Peer to Peer Communication Across Network Translator. Diperoleh dari http://pdos.csail.mit.edu/papers/p2pnat.pdf

Ghosemajumder, S. (2002). Advanced Peer-based Technology Business Models. Advanced Peer-based Technology Business Models

Global Statshot 2015. 3 Agustus 2015. [Web Blog] diperoleh dari http://wearesocial. net/blog/2015/08/global-statshot-august-2015/

Goldberg, M. (1996). Junk collage, nodal points, and cognitive dissonance: William Gibson takes the pulse of the late twentieth century. Addicted to Noise , 2.10 [website] diperoleh dari http://www.addict.com/issues/2.10/html.hifi/Cover_Story/

Gong, Y. (8 December 2014). "Identifying P2P Users Using Traffic Analysis”, Symantec.

Ha, L. and James, E. L. (1998). Interactivity Reexamined: A baseline analysis of early businesswebsites. Journal of Broadcasting \& Electronic Media, 42 (4): 457-474

Hinks, J. 2015 March 06. The Best free torrent clients in 2015. Retrieved from http://www.techradar.com/news/software/applications/best-torrent-client-8-werecommend-1169584

Jones, S. G. (ed.) (1997) Virtual Culture: Identity and Communication in Cybersociety. London: Sage 
Kiousis, S. (2002). Interactivity: a concept explication; New Media and Society, 4(3): $329-54$

Lin, H., 2006, Understanding Behavioral Intention to Participate in Virtual Communities, Cyber Psychology \& Behavior Vol. 9 No.5: 540-545

Lindlof, T. R. and Schatzer, J. (1998). Media Ethnography in virtual space: strategies, limit, and possibilities; Journal of Broadcasting and Electronic Media, 42 (2): 170-189

McMillan, S. J. and Downes, E. J., (1998). Interactivity: A qualitative exploration of definitions and models. Paper presented to the Association of Education in Journalism and Mass Communication, August, Baltimore, Maryland.

McQuail, D. (2011). McQuail Mass Communication Theory. Singapore: Sage

Rheingold, H. (1993). The Virtual Community: Homesteading on the Electronic Frontier. Read, Mass.: Addison-Wesley.

Schulze, H and Mochalski, K. (2009). “Internet Study 2008/2009”. Leipzig, Germany: ipoque. Archived from the original (PDF) on 2014-04-01. Retrieved 3 October 2011.

Severin, W. J. dan Tankard, J. W. (2011). Teori Komunikasi: Sejarah, Metode, dan Terapan di Dalam Media massa Edisi Ke 5. Jakarta: Kencana

Slevin, J. (2000). The Internet and Society. Cambridge: Polity press

Somantri, G. R. (2005). Memahami Metode Kualitatif. MAKARA, JURNAL SOSIAL HUMANIORA, 9(02), 57-65

Thurlow, C. , et al. (2005). Computer Mediated Communication. London: Sage Publication

Turkle, S. (1995). Life on the Screen: Identity the age of The Internet. New York: Simon and Schuster

Turner, J. W., et. al, (2001). Developing an optimal match within online communities: an exploration of $\mathrm{cmc}$ support communities and traditional support: Journal of Communication $51(2): 231-251$

Williams, F., Rice, R. E., and Rogers, E. M. (1988). Research Methods Aand The New Media. New York: The Free Press

Yudha, F. dan Prayudi, Y. (2013). Teknik Eksplorasi Bukti Digital Pada File Sharing Protokol SMB Untuk Mendukung Forensika Digital Pada Jaringan Komputer, Conference Paper Retrieved from KNIF, Konferensi Nasional Informatika ITB Bandung http://www. researchgate.net/publication/257938862 